\title{
Las fuentes monumentales como elementos estructuradores del urbanismo antiguo. El ejemplo de la ciudad de Tarraco
}

\section{Monumental fountains as structuring elements of ancient urbanism. Tarraco, a case study}

\author{
Ana Costa Solé \\ Universitat de Girona (UdG). Laboratori d'Arqueologia i Prehistòria \\ Plaça Ferrater i Mora 1, Campus Barri Vell, E-17004 Girona \\ nymphaeum82@gmail.com
}

El mundo romano estructuró una serie de elementos, algunos dispersos por el territorio, otros estructurados dentro de la trama de las urbes con una finalidad muy concreta: fijar una serie de puntos relevantes sobre el territorio, marcar esos hitos como elementos de control territorial y social, y generar espacios públicos bien delimitados dentro de las ciudades, buscando transmitir una serie de valores y mensajes propagandísticos, así como evidenciar el poder del Imperio y de la clase política dentro de su territorio.

\section{PALABRAS CLAVE}

URBANISMO, FUENTES MONUMENTALES, NINFEOS, EVERGETISMO

The Roman world structured a series of elements, some scattered throughout the territory, others structured within the fabric of the urbes with a very specific purpose: to set a series of relevant points on the territory, to mark these milestones as elements of territorial and social control, and to generate well-defined public spaces within cities, seeking to transmit a series of values and propagandistic messages as well as evidence of the power of the empire and the political class within its territory.

\section{KEYWORDS}

URBANISM, MONUMENTAL FOUNTAINS, NINFEO, EVERGETISM 
El desarrollo urbanístico de toda ciudad romana necesitaba una serie de elementos indispensables: centros termales, fuentes públicas, ninfeos monumentales, etc., que requerían una planificación previa orientada a la obtención y la garantía de los recursos hídricos precisos para su pleno desarrollo. Las mejoras en ingeniería conllevaron la aparición en el suburbio y en el interior mismo de las urbes de elementos tales como acueductos, castellum aquae, sifones, canalizaciones, alcantarillado, etc. Estos elementos conformaron el sistema de captación, transporte y distribución del agua, que permitió dotar las ciudades de una serie de cosas fundamentales en lo práctico, pero también en cuanto a propaganda y embellecimiento de la trama urbana (Costa, 2011: 141).

Si bien el mundo griego nos ofrece grandes ejemplos de abastecimiento hidráulico dentro de las ciudades, fue el mundo romano el que alcanzó sus cotas óptimas, garantizando flujos regulares y constantes de agua, así como la creación de sistemas de saneamiento y evacuación de aguas residuales mediante complejos sistemas de alcantarillado. La literatura romana especializada nos da referencias de ello, destacando Vitrubio y Frontino como recopiladores principales de estas obras de ingeniería (Hodge, 2000: 39).

En relación con los sistemas de distribución de agua en el interior de las ciudades, en este artículo queremos destacar el papel de las fuentes monumentales. Concretamente, nos interesa el papel que desempeñan los elementos que intervenían en la vertebración del urbanismo, siendo, además de un elemento utilitario, un hito o barrera que delimitaba y daba relevancia a los espacios urbanos de interés. Las fuentes monumentales hacían las funciones de barrera arquitectónica, ayudaban a delimitar el espacio en las tramas urbanas y, dentro de estas, enmarcaban espacios públicos con una carga simbólica importante. En este artículo presentaremos diferentes ejemplos localizados en la ciudad de Tarragona en época romana, gracias a los cuales podremos observar su relevancia y función dentro de la ciudad y su relación con distintos espacios públicos.

\section{La Tarraco romana. Urbanismo y desarrollo}

El desarrollo de la Tarraco romana vino condicionado por una topografía particular que facilitó la creación de una serie de terrazas que descendían hasta el puerto, dando su particular imagen al conjunto urbano (Mar, 1992: 164). En época julioclaudia, y en la terraza baja, se localizaba una basílica jurídica con una aedes Augusti. El foro, que existía ya desde época republicana, como demuestra la epigrafía recuperada, se encontraba en la frontera de la terraza inferior, marcando el límite en un talud que desembocaba en la zona portuaria de la ciudad (Mar, 1992: 164). La parte oriental de la fachada marítima fue ocupada ya en época tardorrepublicana por edificios de uso práctico e industrial vinculados al puerto marítimo de la ciudad. En el siglo i aC se generó toda una red de espacios públicos relacionados con el puerto: desde almacenes (horrea) a fuentes que garantizarían el abastecimiento de agua, etc. Esta transformación se debe sobre todo a los cambios urbanísticos propiciados por la 
bonanza económica y política de la ciudad (Ruiz de Arbulo et al., 2015: 129). A partir del cambio de era y a lo largo del siglo i dC, la fachada marítima de Tarragona se dividió en dos: una zona monumental con edificios públicos y un entorno embellecido que se extendía por la zona oriental de la fachada marítima de Tarragona. Esta presentaba un carácter residencial y lúdico, como lo demuestran algunos de los edificios que la arqueología ha sacado a la luz: el teatro y su zona anexa, las termas de la calle Sant Miquel (Ruiz de Arbulo et al, 2015: 133-135), etc., y también las termas localizadas en la actual calle Apodaca. En contraposición a la zona monumental, encontramos la fachada occidental, caracterizada por la creación de edificios funcionales relacionados con el comercio y el puerto. Se trata de una zona mercantil que se desplazó hacia las proximidades del río Francolí y su desembocadura. A poniente del promontorio sudoccidental de la ciudad, también se localizó la extensión del área portuaria, documentada bajo las actuales calle del Vapor y avenida Vidal i Barraquer. Esta reestructuración conllevó la creación de una extensa red de vías, porticados y zonas de almacenamiento que se prolongaron por la línea de costa (Macias, 2011: 198). Todos estos elementos dispuestos en terrazas artificiales se inscriben en el proceso de mejoras monumentales de la ciudad (Pociña y Remolà, 2001: 92), creando una escenografía que se convirtió en la carta de presentación de la ciudad romana de Tarraco. Entre los siglos I y in se produce el momento de máximo esplendor de la fachada marítima de la ciudad, con la culminación del proceso urbanístico de esta zona (Macias y Remolà 2010: 133). A partir del siglo II, estas estructuras entraron en un proceso de regresión demostrando que ya no era necesaria tal cantidad de almacenes y estructuras portuarias (Macias, 2011: 198-199).

El foro de Tarraco se fue construyendo a medida que, en paralelo, evolucionaba la ciudad. En época de Augusto se produjo una gran revolución urbanística y monumental que incidió en los espacios estratégicos y más representativos de la urbe romana. Entre estas grandes transformaciones se crearon dos plataformas gemelas que limitaban con el acantilado que dominaba el puerto de la ciudad. La nueva plaza estaba presidida por la basílica jurídica y el aedes Augusti en posición preeminente, sustituyendo el antiguo templo dedicado a Júpiter de la plaza republicana (Mar et al., 2012: 259). Las reformas urbanísticas de la zona baja de la ciudad, junto a la línea de costa, llegaron a su momento de mayor esplendor en el siglo i dC.

A grandes trazos, este fue el proceso urbanístico de la ciudad de Tarragona en época romana hasta el siglo II dC. Una vez dispuesto el escenario, pasaremos a ver los distintos sistemas de captación, abastecimiento y distribución hídrica de la ciudad, que permitieron desde el primer establecimiento ibérico a la posterior fundación romana y, fruto de ello, la aparición de distintos ejemplos de fuentes monumentales.

\section{Abastecimiento hídrico de la ciudad}

La primera fuente de abastecimiento de Tarragona fue sin duda el río Francolí, antiguo Tulcis, un elemento fundamental para la ubicación del oppidum ibérico de Kesse y la pos- 
terior ciudad romana. El tramo final del río acababa en una gola a los pies de la colina formando una vaguada que se utilizó como zona portuaria, al quedar en parte protegida por ella. Esta característica favoreció con toda probabilidad el asentamiento ibérico y el posterior interés romano por el lugar como base invernal durante la Segunda Guerra Púnica (Ruiz de Arbulo et al., 2015: 118).

En paralelo al caudal del río Francolí, encontramos otra fuente natural de agua potable, la conocida como cueva urbana, y una red de pozos asociados a ella que se localizan a lo largo de la ciudad, además del conocido cunniculus (Ruiz de Arbulo et al., 2015: 121). En una publicación de 1875, el doctor Cuchí (1875) estudió las propiedades fisicoquímicas de todas las aguas potables procedentes de los diferentes manantiales de Tarragona: las aguas de la plaza de la Font, las de la mayoría de las fuentes y manantiales repartidos por toda la ciudad, así como los pozos afectados durante la explotación de la cantera del puerto. También analizó pozos privados, como los situados en los números 1 y 19 la calle Unió, así como la fuente que brotaba cerca del puerto y que se utilizó como punto de abastecimiento para las naves (Palma, 1958: 47). Las aguas de todos estos puntos tenían la misma composición química, lo que hizo plantear la hipótesis de un origen común (Cuchí, 1875 : 12). Este estudio demostró, por un lado, la riqueza hidrológica de la ciudad y, por otro, el rasgo común que vincula todos esos puntos de abastecimiento: la gran cueva urbana. Seguramente esta gran masa de agua potable fue otra de las causas de la ubicación del oppidum ibérico y posteriormente la ciudad romana, así como la sucesiva vida en torno a este punto de abastecimiento prácticamente inagotable. La cueva urbana y el caudal del río Francolí representan los principales recursos hídricos con que podía contar el oppidum ibérico y la ciudad de Tarragona en época republicana. Esta cueva se sitúa bajo la planta de la ciudad romana, concretamente dentro del perímetro de la muralla tardorrepublicana, al sur del gran complejo foral de época altoimperial (Burés, García, Macias, 2000: 79). La ciudad de Tarragona se sustenta en un tipo de suelo muy complejo, compuesto por tres tipologías diferentes: acuíferos de formaciones calcáreas y macizo de dolomías; acuíferos de formaciones calcáreas, calcarenitas y roca sedimentaria y, por último, acuíferos de formación mixta de las depresiones del neoceno y el cuaternario (Burés, García, Macias, 2000: 83). La relación entre los fenómenos cársticos y el desarrollo urbano es un hecho ya atestiguado en las ciudades griegas y las colonias: Corinto, Atenas, Delfos, Rodas, Aso, Priene, Mileto, Siracusa, Agrigento, etc. (Burés, García, Macias, 2000: 83) y Clunia dentro del ámbito ibérico (Cuesta, 2010: 167) (fig. 1).

Tanto la cueva como algunos de los pozos ya estaban documentados en el siglo XIX, pero como consecuencia de los cambios urbanísticos de la ciudad estos espacios quedaron en el olvido hasta mediados de los años noventa, cuando las obras de un aparcamiento facilitaron el redescubrimiento de la gran cueva y el sistema cárstico subterráneo de la ciudad (Burés, García, Macias, 1998: 183-196). La obra de Albiñana y Bofarull de 1849 narra cómo se localizó la boca del conocido pozo Cartanyà, que en su momento se consideró uno de los testigos del cunniculus excavado en la ciudad de Tarraco, que forma una galería subterránea 13 m por debajo del nivel de la antigua ciudad y permite afirmar la 
Figura 1. Planta de Tarragona con la ciudad romana sobrepuesta y la indicación de situación de los diferentes espacios:

1. Ninfeo del espacio anexo al teatro,

2. El ninfeo de los Jardines del Vapor,

3. La Font del Lleons, 4. La fuente monumental de la plaza del Macellum, 5. El ninfeo del Collegium Fabrum (fuente: Ruiz de Arbulo et al., 2015: 120, fig. 2).

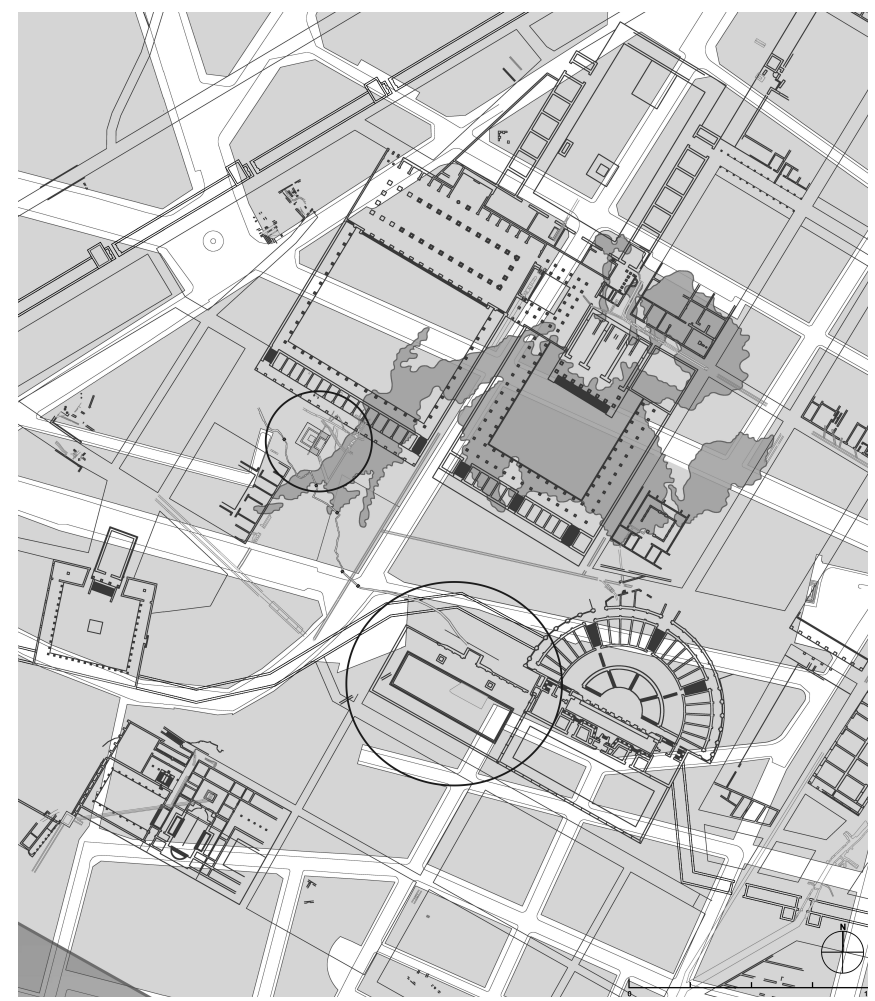

presencia de un extenso sistema subterráneo de conducción de agua. La práctica romana de excavar galerías era heredera de la larga tradición etrusca de excavaciones subterráneas, destinadas fundamentalmente a trabajos hidráulicos (Wilson, 2000: 306-309). No se tienen datos cronológicos de la excavación de la galería, pero la ejecución del proyecto técnico, la definición del trazado y el emplazamiento de los putei necesarios se puede considerar un criterio ante quem para la datación de los trabajos. La hipótesis que surge para fechar el trabajo considera que el proyecto técnico y la excavación de las galerías se habrían desarrollado con anterioridad o en el mismo período en que se produjo la gran transformación urbanística de la ciudad de finales del siglo II aC. Esta suposición se basa en que dentro de una ciudad plenamente urbanizada no hubiera sido posible realizar la obra y ubicar los pozos pertinentes a lo largo del trazado del cunniculus. La obra hidráulica se explica gracias al origen militar de la ciudad romana y las necesidades derivadas de las infraestructuras portuarias. Tarraco era un núcleo militar entre la Segunda Guerra Púnica y las guerras celtibéricas, con un puerto al que llegaban grandes cantidades de militares y de población. Por lo tanto, hay que pensar en unas necesidades importantes de almacenamiento y distribución de agua potable para abastecer tropas y barcos, hecho que explica, por ejemplo, la cisterna de agua localizada en las inmediaciones de la zona del teatro (Remolà y Ruiz de 
Arbulo, 2002: 34). La presencia del cunniculus, así como la tipología de una de las fuentes monumentales del área portuaria, la Font dels Lleons, son elementos cuyo análisis estilístico indica una influencia helenística e itálica dentro de la Tarraco republicana (Macias y Puche, 2004: 43). La dirección que toma la galería del cunniculus apunta la posibilidad de que se dirigiera a la zona ocupada con posterioridad por el teatro, donde la arqueología determinó la presencia de estructuras portuarias, depósitos de época republicana, anteriores a la construcción del edificio teatral (Ruiz de Arbulo et al., 2010).

Con la fundación de la colonia y a partir de la época de Augusto, el suministro de agua a Tarraco se reforzó con la construcción de tres acueductos, uno procedente del río Gaià y dos del Francolí (Remolà y Ruiz de Arbulo, 2002: 33; Ruiz de Arbulo et al., 2015: 129). El acueducto más conocido tomaba las aguas del Francolí a la altura de Puigdelfí, a una cota aproximada de 92 m.s.n.m.; circulaba paralelo al cauce y posteriormente se adaptó a las curvas de nivel de un terreno irregular y accidentado. Ya muy cerca de la ciudad, la conducción debía atravesar un barranco, que fue sorteado gracias a un gran puente conocido hoy día como Pont del Diable o de les Ferreres. Constituyen su base once grandes arcos de tipo piramidal que sustentan una segunda arquería que se adapta a los taludes laterales, formada por veinticinco arcos más pequeños sobre los cuales se encuentra el specus (Remolà y Ruiz de Arbulo, 2002: 33; Ruiz de Arbulo et al., 2015: 129). Una segunda conducción, derivada del río Gaià, llevaba el agua a la parte media y baja de la ciudad. El seguimiento del trazado de la conducción romana ha evidenciado tramos de galería subterránea, de galería cubierta con bóveda y algunos al aire libre (Ruiz de Arbulo et al., 2015: 131) y una tercera, que tenía su origen de nuevo en el río Francolí. Este acueducto ha sido considerado el origen del conocido Rec Major, principal medio de suministro de agua de la Tarragona medieval y moderna, acueducto que abastecía la parte baja de la ciudad y permitiría el funcionamiento de una reserva de agua en el entorno portuario, siendo el origen lejano del abrevadero y fuente portuarios activos desde el siglo Xvi (Remolà y Ruiz de Arbulo, 2002: 33-34; Ruiz de Arbulo et al., 2015: 132).

Una vez expuesta la evolución urbanística de la ciudad y los sistemas de abastecimiento de agua que se fueron adaptando y creciendo con las nuevas necesidades, pasamos a exponer algunos ejemplos de fuente monumental y como estas incidieron en el desarrollo monumental de la Tarraco romana (fig. 2).

\section{El espacio anexo al teatro}

La construcción del teatro de Tarragona se produjo alrededor del cambio de era. No resulta algo extraño, ya que en época de Augusto la construcción de teatros en todo el imperio fue una constante, fruto de la promoción que hizo el mismo emperador. También fue relevante la buena acogida de las élites locales que vieron, en el hecho de apoyar la casa de Augusto, una gran posibilidad de ascenso político (Jiménez, 1993: 232). 


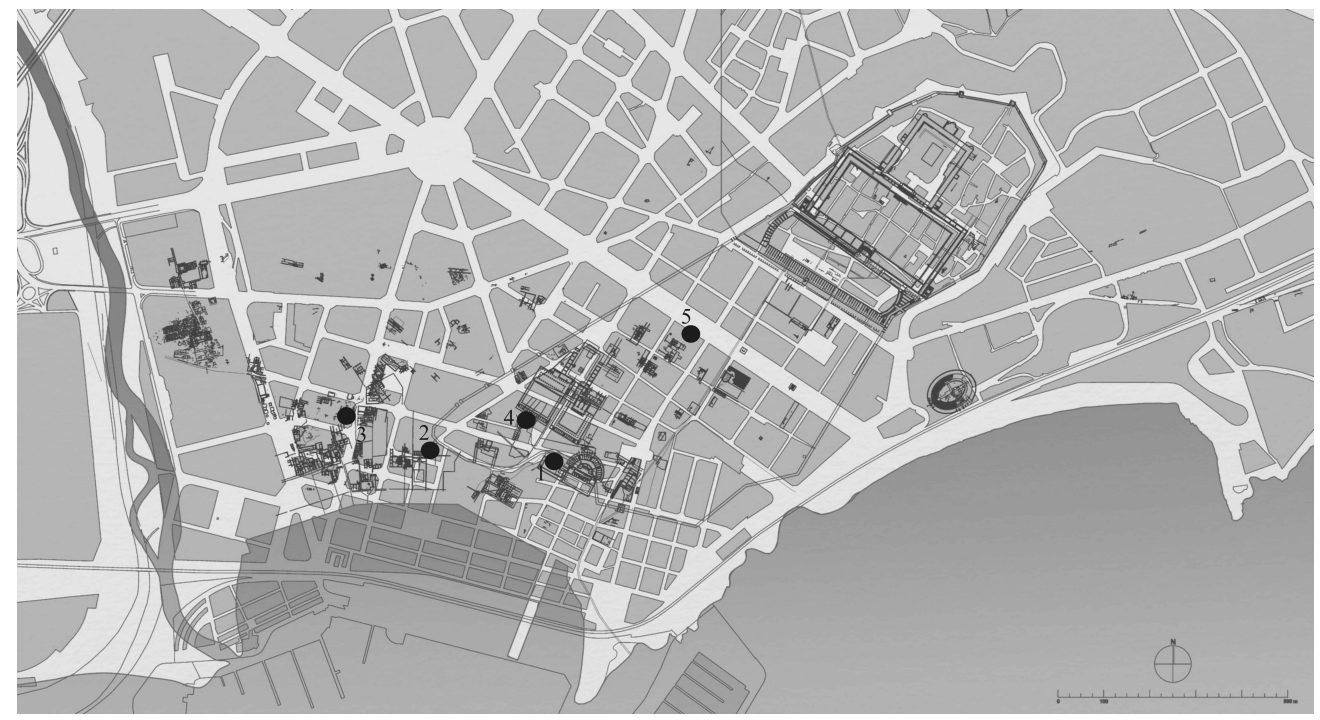

Figura 2. Situación de la cueva urbana y el cuniculus en relación con la planta de la ciudad romana. Marcados con sendos círculos localizamos el ninfeo del área anexa al teatro y la fuente de la plaza del Macellum (fuente: J.A. Beltrán y R. Mar).

La cronología del teatro de Tarragona nos traslada a un momento posterior al año 31 aC. Este dato se confirmó durante los trabajos arqueológicos de principios de los años ochenta, puesto que en la tercera década antes de nuestra era se construyó uno de los almacenes portuarios que precedieron a la construcción del teatro. Esta obra debió ejecutarse con mucha rapidez y se amortizó igual de rápido, puesto que sobre el año $4 \mathrm{dC}$ el edificio del teatro ya estaba terminado (Mar et al., 2012: 321).

Durante los trabajos arqueológicos dirigidos por M. Roca llevados a cabo entre 1982 y 1984 se localizó toda una zona anexa al teatro que estaba presidida por un gran ninfeo monumental. Aunque la excavación de la zona fue parcial y algunas estructuras se encontraban en muy mal estado, podemos hablar de un hallazgo muy significativo (Mar, 1992: 164-166; Mar, Roca y Ruiz de Arbulo, 1993: 16; Mar et al., 2010: 177). Se trata de un ninfeo de cámara, abierto en el centro de un largo muro ciego con pilastras, que decoraba arquitectónicamente el desnivel natural y presidía una zona abierta (Ruiz de Arbulo et al., 2015: 123-125). La anchura del muro de pilastras se dedujo partiendo de la base de que el ninfeo ocupaba el eje axial del recinto y, gracias a la conservación del muro que delimita con la fachada del teatro, se infirió que se trataba de una fachada de unos $55 \mathrm{~m}$ de largo en la que se insertó un ninfeo de unos $5 \mathrm{~m}$ de anchura y 3 de profundidad (Mar, Roca y Ruiz de Arbulo, 1993: 21-22). Enmarcando la cámara central que daba salida al agua, se localizaron dos basamentos cuadrangulares de grandes dimensiones a los que se han asociado dos jarras monumentales (Mar, Roca, Ruiz de Arbulo, 1993: 16). Solo se conservan seis fragmentos de estas piezas, realizadas en mármol del Proconeso (Koppel y Rodà, 1996: 136), cuya decoración era de temática 
vegetal —hojas de acanto, hojas lobuladas, flores, etc.- (Koppel y Rodà, 1996: 136137) (fig. 3).

Este recinto también disponía de una gran piscina que ocupaba la zona central. Obrada con paredes de sillares y revestimiento interno de opus signinum, presentaba un zócalo superior con coronación modulada y una profundidad de casi $3 \mathrm{~m}$, tal como demostraron dos sondeos realizados en los años 1976 y 1981 (Mar, Roca y Ruiz de Arbulo, 1993: 16). No se pueden dar más datos de la piscina, ya que se desconoce la situación de los otros tres muros de la obra; se puede especular sobre su longitud, siempre teniendo en cuenta su entorno inmediato y las otros hallazgos arqueológicos del entorno. Los restos de este recinto se prolongan bajo la cimentación de un almacén ubicado en la calle Santa Tecla (Mar et al., 2012: 290). (fig. 3).

La construcción de un ninfeo en el entorno del teatro respondía a la necesidad de un espacio escenográfico, de ahí la similitud con el teatro, pero con un aura más bucólica que nos remite a elementos de la naturaleza y del imaginario mitológico romano. El manantial de agua, insertado en el muro que crea una terraza artificial, ayuda a definir una plaza abierta y de carácter monumental que complementa la estructura del teatro. La tarea de recrear un espacio natural, la cueva donde brota el agua, pero con una presencia monumental, intentaba mostrar la grandeza y la riqueza de la ciudad, así como la permanencia del contacto con algo que hacía grande el hombre, la naturaleza (Costa, 2017: 421).

\section{El ninfeo de los jardines del Vapor}

Entre los años 2000 y 2002 se realizó una serie de trabajos arqueológicos que pusieron al descubierto un conjunto de estructuras relacionadas con el puerto de Tarraco; se localizan entre las actuales calles Jaume I, Smith y Vapor. Los restos romanos se construyeron muy próximos a la línea de costa, en la zona del puerto romano, identificado gracias al rompeolas, que todavía existía a mediados del siglo XIx. Esta escollera se sitúa en el espacio actualmente ocupado por la plaza de los Carros; la playa de Tarraco emulaba una media luna y era un punto de carga y descarga de mercancías (Bea, 2006: 223-224). Los restos arqueológicos localizados en su momento en la denominada zona UA 15 de Tarragona - en los hoy Jardins del Vapor - demuestran que esta era una zona de almacenes directamente relacionados con el transporte marítimo (Macias et al., 2013: 201-202) (fig. 4).

Entre las estructuras localizadas en esta zona, la que despierta nuestro interés es una fechada en el siglo I dC. Se trata de un ninfeo cuyos restos fueron seccionados por los muros de unas naves industriales modernas, cercanas a la calle del Vapor. De planta circular, presenta seis columnas con sendas bases de piedra arenisca y trabajadas al estilo toscano, sustentadas sobre un muro de piedra unida con mortero de cal. Una segunda estructura circular, menor y ubicada en el centro de la primera, presenta restos de pavimento interno realizado en opus signinum (Bea, 2006: 233). Este sería el lacus, de 2 m de 

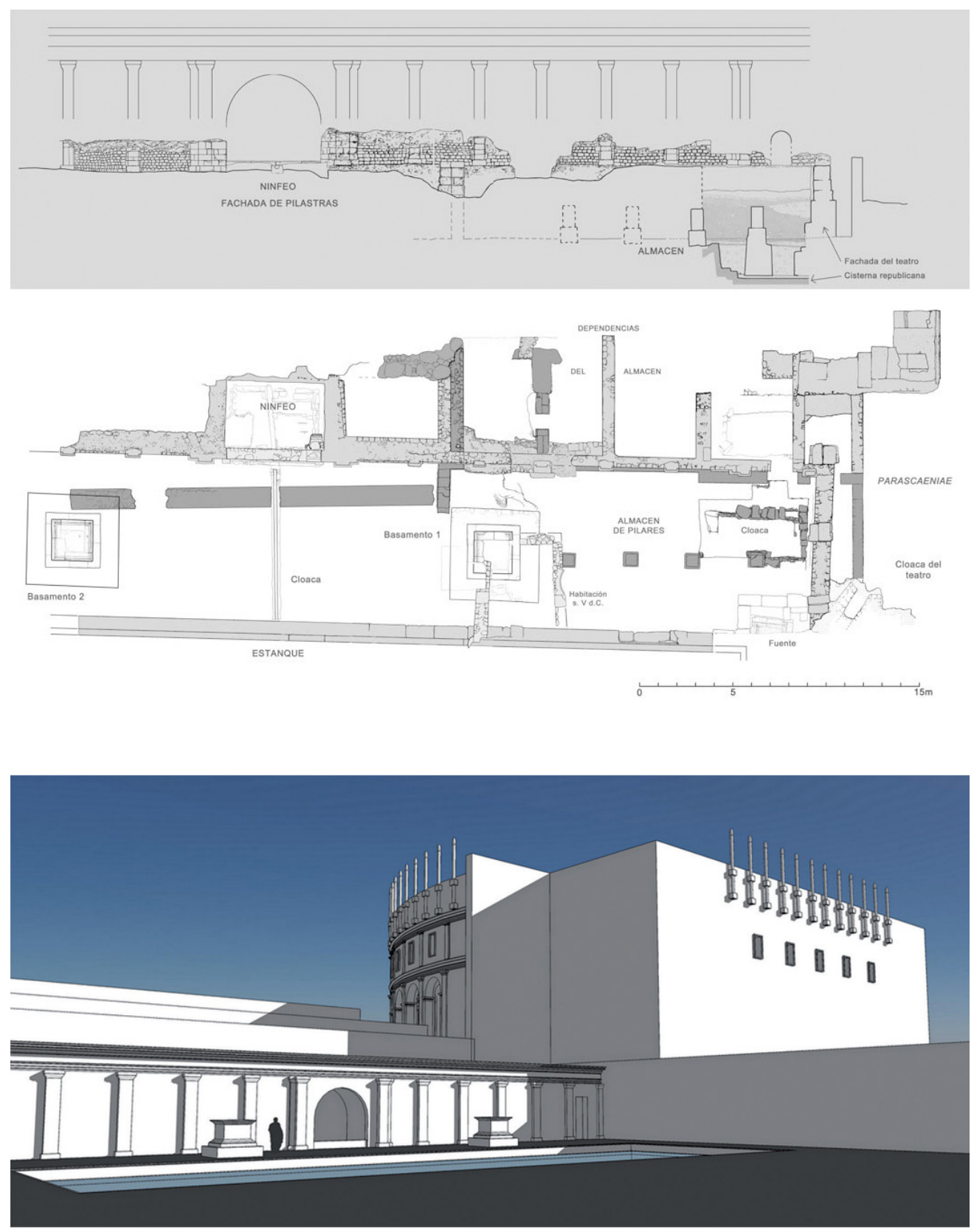

Figura 3. Arriba: planta y alzado con los restos del ninfeo del área anexa del teatro romano (fuente: Mar et al., 2012: 288-289). Abajo: restitución del ninfeo del área anexa del teatro romano (fuente: Ruiz de Arbulo et al., 2015: 124). 
diámetro y un mínimo de $50 \mathrm{~cm}$ de profundidad, que haría las funciones de depósito de agua y donde, podemos especular, habría una estatua u otros elementos decorativos.

La fuente estaba rodeada por una exedra semicircular con una anchura máxima de $13 \mathrm{~m}$. La exedra constaba de un muro semicircular hecho con opus caementicium, de al menos $3 \mathrm{~m}$ de altura, y en el revestimiento interior tenía un estucado de color blanco y azul oscuro, con toques cromáticos rojos, amarillos y lilas. En algunos tramos existiría una decoración arquitectónica a partir de medias columnas adosadas a las paredes. Se ha especulado con la posibilidad de que los muros también estuvieran adornados con franjas y listones de mármol. Sí se localizó una cenefa denticulada entre la pared y la cubierta, realizada con mármol del tipo roso antico. Todos estos elementos ornamentales darían a la fuente un cierto carácter lujoso (Macias et al., 2013: 202).

Esta fuente quedaría integrada dentro de un espacio arquitectónico más complejo, tal vez de carácter multifuncional, integrado en un conjunto monumental (Macias et al., 2013: 202-203); la fuente, al igual que el complejo anexo al teatro, formaba parte de la fachada marítima de la ciudad. La cronología sitúa su construcción en el siglo i dC - momento de grandes obras en toda la ciudad-y estuvo en funcionamiento hasta el siglo III. Las indagaciones arqueológicas, concretamente el estudio de los estratos localizados en el espacio entre la fuente y la exedra, permitieron documentar un incendio y la posterior destrucción del conjunto monumental, donde se alternaban niveles de derribo, cenizas y cremación, y finalmente de abandono. Parece que entre el incendio y el definitivo derribo pasó un tiempo tras el cual la fuente quedó abandonada en el siglo III dC (Macias et al., 2013: 203).

Este ninfeo se presenta como un ejemplo de fuente monóptera, frecuentemente vinculada a los santuarios. Encontramos un posible paralelo para este elemento en la fuente del ágora de Argos, fechada en el siglo I, que presentaba una inscripción dedicada a las ninfas (Neuerburg, 1965: 67). Otro paralelo se encuentra en el foro triangular de Pompeya, donde hay una fuente circular con seis columnas, ricamente decorada y ubicada cronológicamente en el siglo II aC. El foro de Ostia también presentaba una fuente redonda, posiblemente la más similar a la de Tarragona; situada en el centro del foro, al sur del decumanus maximus, se localizaron los restos de una estructura redonda construida con ladrillo de unos 4,5 m de diámetro exterior. Su cronología se sitúa en época de Trajano (98-117). La decoración externa de la obra era de mármol y su interior presentaba seis nichos, algunos de los cuales con agujeros para la llegada de agua y donde muy posiblemente se ubicarían esculturas de divinidades (Glaser, 2000: 448). Parece ser que este tipo de fuentes monumentales fue el que inspiró los baptisterios primigenios (Neuerburg, 1965: 72; Glaser, 2000: 449). El estudio de las fuentes y ninfeos de Italia, que publicó en 1965 Neuerburg, tiene, dentro de las tipologías estudiadas, un apartado para lo que él llama ninfeos redondos. El ejemplo más antiguo que corresponde a esta tipología es la iglesia de Santa María della Rotonda en Albano (Neuerburg, 1965: 65), que dispone de una planta circular con nichos, insertada en una construcción cuadrangular de época de Domiciano. Aunque en un primer momento se presentó como una obra aislada, pertenecía a un complejo termal mucho más amplio. Los principales paralelos, que según los autores pueden 

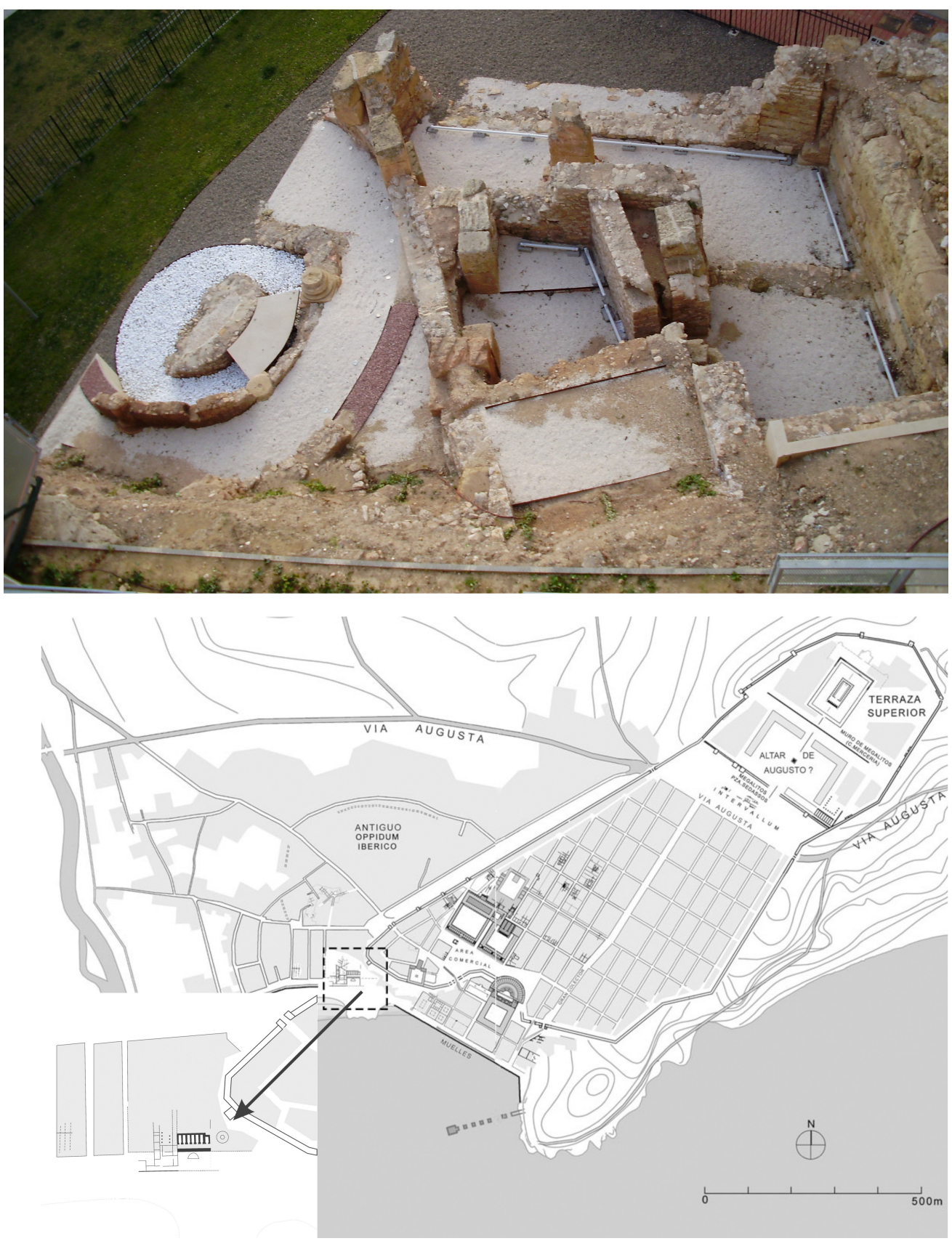

Figura 4. Arriba: estado actual de los restos del ninfeo de la UA 15 (fotografía de la autora). Abajo: situación del ninfeo de la UA 15 en relación con la planta de la ciudad en época julioclaudia (fuente: Mar et al., 2012: 375-376, retocada por la autora). 
evolucionar hacia la fuente localizada en Tarragona, serían en realidad tholoi que cubrían los pozos sacros. Los ejemplos que acompañan esta teoría son el pozo circular localizado en el foro triangular de Pompeya y, sobre todo, el tholos de Marcelo en Pozzuoli, que tenía una fuente circular en el centro. La proximidad de la fuente monumental de la UA 15 con estructuras claramente identificadas como espacios de horrea y comercio nos hace pensar en una estructura de tipo monumental destinada a embellecer un recinto comercial: un tholos macellum (Costa, 2017: 428) (fig. 4). M. García nos da una definición breve y concisa de este espacio indispensable en toda ciudad romana: «El macellum era un mercado alimentario habitual en localidades urbanas tanto de Italia como en las Provincias, en el que se vendían básicamente carne, pescado, especias y otros productos exóticos o importados. Estructuralmente, consistía en un espacio cerrado, a menudo rectangular, con hileras de tabernas y pórticos en torno a un patio central donde habitualmente se erigía un tholos o una piscina» (García Morcillo, 2000: 266). De Ruyt distingue tres tipologías diferentes en cuanto a las estructuras centrales presentes en los macelli, entre las que destaca una de nuestro interés: macellum con tholoi centrales, de tamaño medio, que solían incluir en su interior una fuente o piscina, una estatua, los dispositivos de medidas para el grano y otras mercancías e incluso tabernae (De Ruyt, 1983: 313-315). Las estructuras tipo tholos que caracterizan numerosos macelli se difundieron por las provincias en época de Augusto. Estas estructuras no se limitaban a ser un simple "quiosco" en el centro del mercado; los tholoi, sin una función realmente definida, podían albergar desde una fuente, pasando por una escultura, a espacios de comercio. Esta indefinición en cuanto a la función del tholos ha favorecido la variedad de usos que en él se presentan (De Ruyt, 1983: 295).

\section{La Font dels Lleons}

Otro ejemplo de la mejora del abastecimiento hídrico vinculado a la infraestructura y necesidades de la zona portuaria fue descubierto durante unas excavaciones realizadas entre los años 1998 y 2000 en la parte baja de la ciudad, en un solar en la intersección entre las calles Pere Martell y Eivissa. En este punto se localizaron los restos de una fuente pública que se alimentaba de las aguas procedentes del acuífero subterráneo de la ciudad. Su situación en relación con el puerto nos confirma que se construyó como sistema para garantizar el abastecimiento de agua de este sector suburbano directamente relacionado con la actividad portuaria (Mar et al., 2012: 188). Esta fuente se situó en un camino medieval, conocido como el de la Fonteta, que seguía el curso de la antigua vía romana de acceso a la ciudad. Los principales usuarios de esta fuente fueron marineros, campesinos y gente de paso, que entraban o salían de la ciudad (Remolà y Pociña, 2011: 183) (fig. 5).

La razón de la construcción de esta fuente pasa por constatar la problemática del abastecimiento de agua en la ciudad de Tarraco. En época imperial se crean tanto el acueducto del Francolí como el del río Gaià, pero en época republicana el abastecimiento se 
realizaba gracias a la captación de agua pluvial y sobre todo gracias a la fuente natural del subsuelo de la ciudad, la gran cueva urbana. El aprovechamiento de este gran recurso hídrico, que perdura hoy en día, se inició en el período ibérico, y en época republicana se reforzó mediante pozos y otros artefactos, como es el caso de la Font dels Lleons (Costa, 2017: 439-440). Este artefacto hidráulico se presenta como una adecuación arquitectónica de un manantial natural, vital para el buen funcionamiento de esta zona de la ciudad, caracterizada por las estructuras portuarias, y posteriormente de viviendas privadas pertenecientes al suburbio de la ciudad (Mar et al., 2012: 189) (fig. 6).

La primera fase constructiva se sitúa alrededor del siglo II aC. En la primera etapa, y como consecuencia de la escasa información sobre el empleo en esta zona de la ciudad, solo se puede afirmar que la construcción de esta fuente respondía a una necesidad de abastecimiento mediante el aprovechamiento de los recursos hídricos subterráneos que ofrecía la ciudad en ese momento (Remolà y Pociña, 2011: 183). La observación de las características constructivas de esta primera fase - fuente cubierta, con una columnata frontal, un espacio interno para acceder con un recipiente a la fuente, la sencillez de la estructura, etc.- nos remite a una tipología helenística, tipo krené (Pociña y Remolà, 2002: 43). Se construyó en un punto donde brotaba el agua de la tierra, no había ningún sistema de canalización ni transporte; por lo tanto, es un ejemplo de fuente tipo krené asociada a un manantial (Costa, 2017: 434-436).

La segunda fase constructiva nos lleva al período altoimperial. A inicios del siglo i; en un contexto de reforma y proceso monumental urbanístico general, la fuente se transformó y pasó a adquirir el aspecto de una cisterna. Esta reforma respondería a una necesidad de preservar la higiene del agua, sobre todo teniendo en cuenta que el entorno urbano de la fuente vive un período de expansión urbanística y de grandes proyectos constructivos. Con la reforma viaria de la época de Augusto, se definieron los accesos a la ciudad y la fuente, ahora cubierta, quedó asociada a un entramado viario que se hizo más denso con el paso del tiempo. Los restos de múltiples monumentos funerarios indican que la fuente se encontraría situada al lado de una de las principales vías de acceso a la ciudad (Remolà y Pociña, 2011: 185). El elemento constructivo que caracteriza esta segunda fase es un muro de fachada, situado donde anteriormente se hallarían las columnas del porticado de la fuente. Nos encontramos con un cambio de tipología, transformándola en un receptáculo con un acceso bien definido al gran volumen de agua. En este muro se dispusieron tres brocales con forma de cabeza de león, que garantizaban la salida del agua. Por modulación, donde debería haberse situado un cuarto brocal, se abrió una puerta. Esta, elevada en relación con la cota de circulación y con unas medidas de 1,06 m de ancho y 1,50 de alto, respondería a la necesidad de facilitar el acceso al interior de la cisterna, para realizar las tareas de limpieza que garantizaban la higiene y la salubridad del agua (Pociña y Remolà, 2002: 44; Ruiz de Arbulo et al., 2015: 128; Costa, 2017: 436-438). Encontramos varios paralelos para esta tipología: una fuente de Ucubi (Córdoba) o el sistema de cisterna que se encontró en el puerto de Leptis Magna; también presenta similitudes, pero solo en su estructura interna, con uno de los castellum aquarum de Pompeya (Pociña y Remolà, 


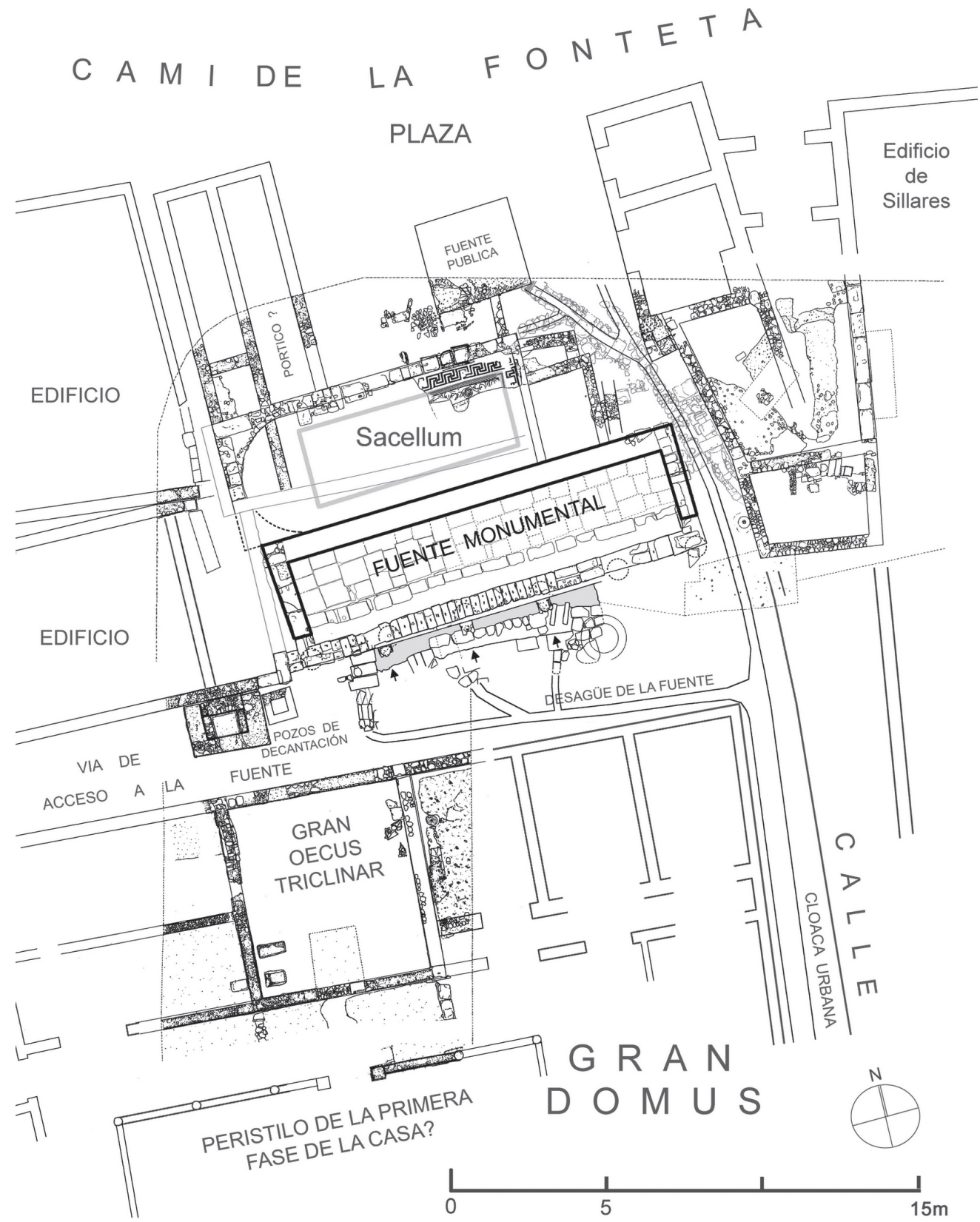

Figura 5. Planta de los restos de la Font dels Lleons (fuente: Ruiz de Arbulo et al., 2015: 126). 

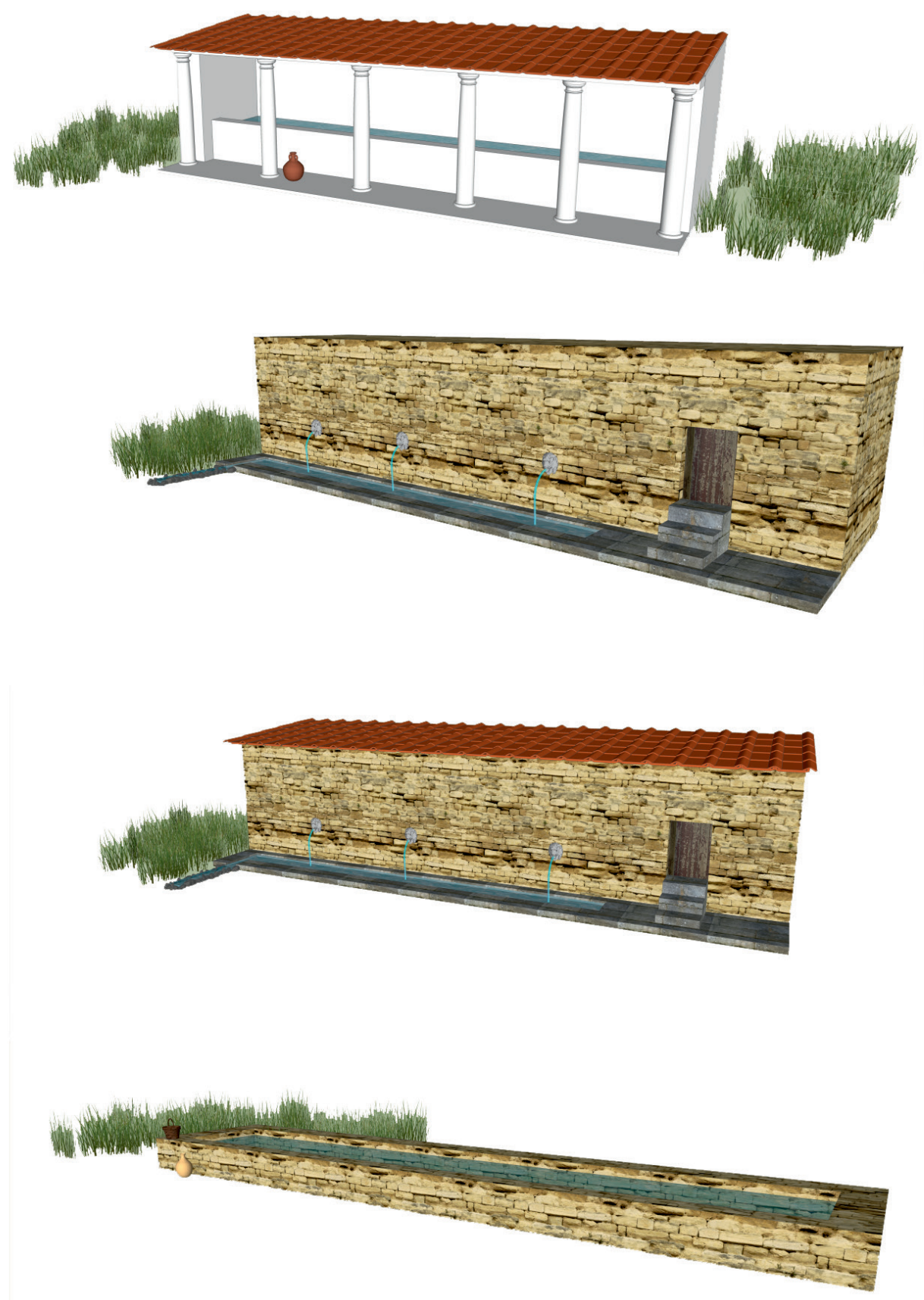

Figura 6. Restitución de las fases de la Font dels Lleons (fuente: dibujo de la autora). 
2002: 44). En Ostia Antica encontramos un conjunto de seis fuentes situadas en el entorno de la región II isla IX. Se trata de seis fuentes a baluetto que servían para garantizar agua potable a dos grandes insulae. Estas seis fuentes tienen el mismo aspecto: rodeadas por tres de sus lados por un suelo de travertino donde se trabajó un canal por el que fluía el agua sobrante. En este canal que discurría por el frontal de la fuente se localizaron dos encajes para depositar las ánforas u otros utensilios cerámicos para recoger el agua. El revestimiento, tanto interior como exterior, era de opus signinum blanquecino (Ricciardi y Scrinari, 1996: 114-115, figs. 198 a 202).

En el último cuarto del siglo I dC dos de los manantiales, el central y el oriental, quedaron obstruidos por los sedimentos del agua. Este incidente provocó que solo quedara en uso el manantial occidental, que se prolonga hasta finales del s. II-inicio del III. La prolongación en el tiempo del uso de este único manantial se demuestra gracias a la estructura semicircular que recogía el agua y que redirigía la sobrante hacia una alcantarilla de grandes dimensiones situada hacia el sureste (Remolà y Pociña, 2011: 187). También se produjo un cambio en la cubierta de la cisterna, que dejó de ser de vuelta de sillares y pasó a ser un techo de armadura de madera revestido exteriormente con tegulae y opus signinum a una vertiente, como demostraría el hecho de que se añade una hilada de sillares al muro de fondo situado al norte (Remolà y Pociña, 2011: 187). A mediados del siglo III, el último manantial también se colapsó y se practicaron agujeros en la fachada para poder extraer el agua, ahora ya de manera muy precaria, mediante la inmersión de recipientes.

El último cambio sufrido por la fuente llega en época tardoantigua. En algún momento entre los siglos III y IV, el techo de la cisterna se colapsó y cayó sobre el pavimento. Los escombros no se retiraron. Gracias a la inmersión permanente dentro del agua de las vigas y tablones que formaron la estructura interna del techo de la cisterna, estas se conservaron y fueron extraídas durante el proceso de excavación (Pociña y Remolà 2002: 45). Los restos del techo quedaron depositados sobre una gran capa de limo y arena, lo que demuestra una dejadez en la limpieza de la cisterna desde tiempo atrás, antes del derrumbe. Aun con la problemática de la falta de mantenimiento, reflejada en la progresiva degradación de la estructura de la fuente, se siguió utilizando durante toda la antigüedad tardía. En el interior de la cisterna se continuaron depositando arena y restos orgánicos. En este momento, la extracción de agua se realizaba mediante la inmersión de pequeños recipientes asidos a una cuerda desde la parte superior de los muros, en los que han quedado marcas de rozamiento de las cuerdas. El uso, por los materiales cerámicos localizados en el interior y los alrededores de la fuente, se limita a la etapa de la antigüedad tardía, pero el hecho de que el camino que bordea la fuente tenga el nombre, en época medieval, de camino de la Fonteta, parece indicar un uso prolongado de la captación aún en esta época. La fase final, con la piscina llena de limo y otros restos, se caracterizó por la excavación de pozos que aprovechaban la riqueza hídrica del subsuelo, ya desde un punto de vista privado (Remolà y Pociña 2004: 65). 


\section{La fuente monumental de la plaza del macellum}

La orografía del terreno sobre el que se sustentó el foro de la colonia de Tarraco era notablemente irregular, con una fuerte pendiente hacia el lado sur. Este hecho obligó a crear unas estructuras, en este caso un criptopórtico, que soportara y permitiera la regularidad de la plaza donde se situaron la basílica y el aedes. Este criptopórtico sustentaba el porticado que decoraba el interior de la plaza y, detrás de él, se edificó una serie de locales, con acceso desde el interior del ambulacro porticado. Para sustentar esta hilera de tabernae, se edificó una serie de construcciones con cubierta de bóveda que las soportaban (Mar et al., 2010: 259). Por otro lado, encontramos una fila de tabernae que cierra la plaza del foro, a una cota inferior a la plaza, por su lado sur. En un momento cronológicamente no determinado, según R. Mar (Mar et al., 2012: 256), las dos tabernae que coinciden con el eje de la basílica jurídica sufrieron una transformación. Fueron unificadas con la construcción de un ábside semicircular, del cual solo queda su cimentación. Esta transformación se ha interpretado como la creación de una gran schola, en relación con la localización de dos bustos esculpidos: uno de Tiberio y otro de Nerón César. Este hallazgo escultórico ha ayudado a establecer la hipótesis de que el espacio funcionaría como un aula de culto imperial (Mar et al., 2012: 256). Ante esta hilada de tabernae se localizó un complejo sistema de canalizaciones que formarían parte de un porticado no conservado (Mar et al., 2012: 256). Ante el porticado se extendía una plaza, interpretada como una zona pública asociada a un área de mercado (Macias, 1997: 61) donde, en relación con las conducciones de agua y otros restos que detallaremos a continuación, se ha determinado que se localizaría una fuente monumental (Mar et al., 2012: 256). En 1995, J. M. Macias dirigió una excavación en el solar $n .^{\circ} 32$ de la calle Gasòmetre de Tarragona. Se localizó allí una serie de cimentaciones labradas en mampostería de piedras pequeñas y medianas de factura irregular y ligadas con mortero de cal de coloración blanca u opus caementicium (Macias, 1997: 42). De esta estructura nacía una canalización labrada en la roca que iba a parar a un colector (Macias, 1997: 61) (fig. 7). Estos restos, ciertamente fragmentarios, han sido interpretados como una fuente monumental, relacionada con la plaza pública y el macellum de Tarragona (Mar et al., 2012: 256). La aparente sencillez con la que se ha restituido la fuente, siempre teniendo en cuenta los escasos restos que han quedado de ella, podría hacer pensar en una simple fuente de calle. Según J. Richard (2008), si se localizan restos de una estructura donde la arquitectura y la decoración han sido tratadas con gran énfasis, dejando en un segundo plano el agua, estaríamos ante un ninfeo de tipo monumental ideado para garantizar una necesidad estética y/o propagandística. Por el contrario, una fuente que presente una gran complejidad en el sistema de abastecimiento hidráulico, y que priorice la extracción de agua por encima de la decoración o la arquitectura, nos mostraría un arreglo hidráulico meramente utilitario (Richard, 2008: 274). Debemos tener presente en todo momento que, dados los pocos restos que han quedado de la fuente, esta podría ser más compleja, e incluso presentar decoración escultórica o algún epígrafe. No conviene descartar ninguna opción y sí valorar las diferentes posibilidades (Costa, 2017: 455). 


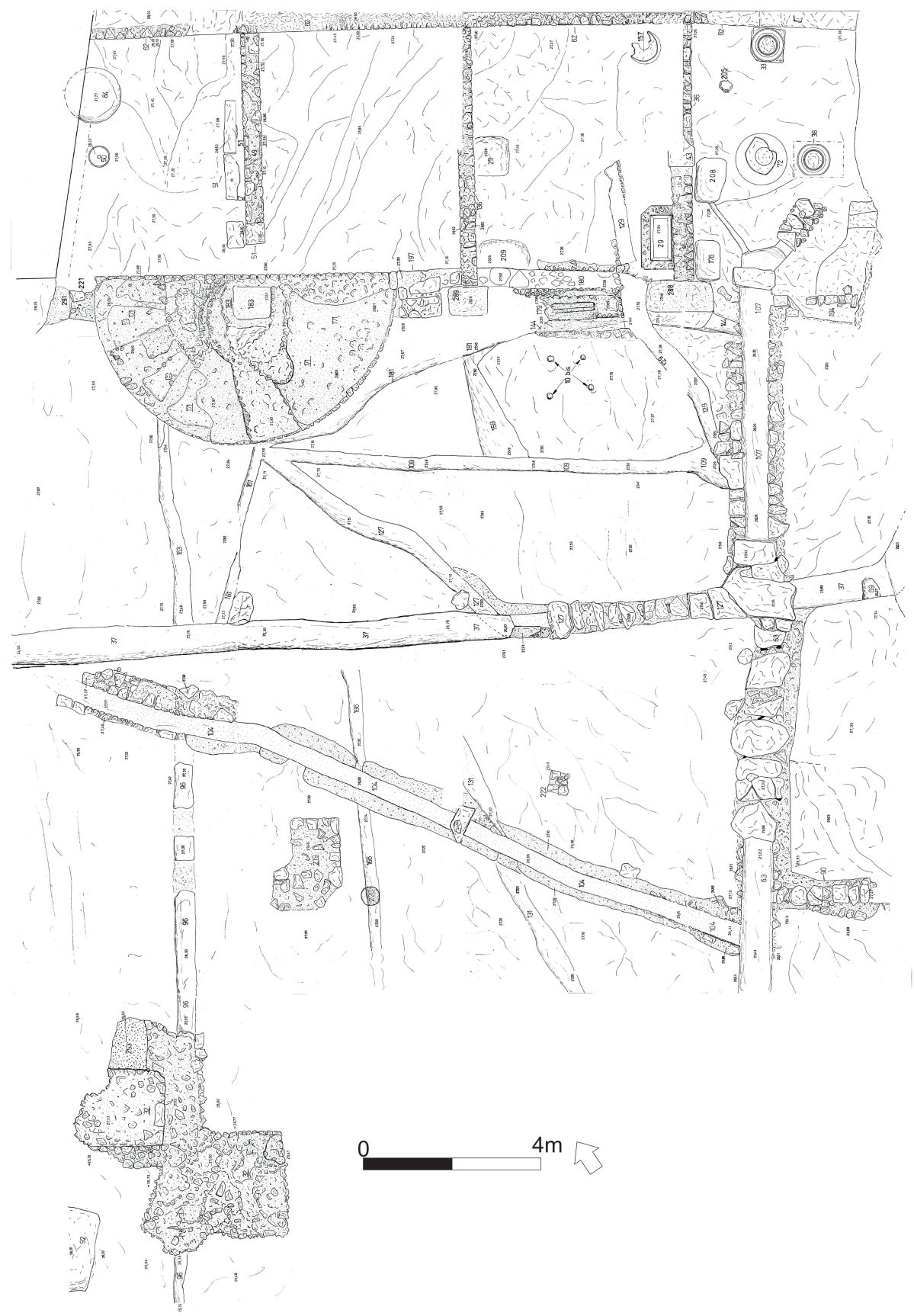

Figura 7. Planimetría de los restos localizados en la calle Gasòmetre n. ${ }^{\circ} 32$ de Tarragona (Macias, 1997). 
La fuente y la explanada en la que se inserta quedan delimitadas por elementos muy relevantes de la ciudad de Tarraco: el foro, el teatro y el templo dedicado a Tutela. La fuente se presenta como un elemento propio de la plaza, no dependiendo de ningún otro edificio y es precisamente esto lo que la hace relevante. Esta plaza se ha considerado un espacio idóneo para celebraciones, liturgias y procesiones, tal como sucedía en Bilbilis, donde el teatro y el santuario de culto imperial estaban unidos por un espacio público de circulación, o en el caso de Mérida, donde el santuario de culto imperial se encontraba en el mismo eje que el teatro (Mar et al., 2012: 338). Estas vías se interpretan como espacios procesionales, vinculados a la veneración de la domus augusta (Mar et al., 2012: 338). Pero ¿qué papel desempeña una fuente monumental en este espacio? Como ya hemos referido en la introducción, la época de Augusto fue un momento de gran esplendor en cuanto a la construcción de fuentes públicas. La creación de grandes espacios de representación, donde el agua tiene un papel fundamental, es casi un cliché en las principales ciudades del Imperio y Tarraco no es una excepción. La interpretación que hacemos de este artefacto nos remite a la finalidad los grandes lacus que se sitúan en torno a los templos de los foros de diferentes ciudades (Costa, 2107: 456). Al igual que en el caso de Empúries, Barcino, Mérida o Luna (Ruiz de Arbulo, 1991: 26; Álvarez y Nogales, 2003: 185-214; Hauschild, 1994: 197; Reis, 2010: 291; Costa, 2017: 470), estos grandes depósitos de agua cumplen una función delimitadora del espacio; la fuente situada en esta plaza cívica de Tarraco ayuda a crear un espacio libre donde se llevaban a cabo ceremonias litúrgicas relacionadas con la familia imperial. La situación de la fuente, bloqueando el paso de una de las calles que conducían a esta plaza, garantizaba que a ella, sobre todo en el lado norte, solo se pudiese acceder a pie. Hay que recordar la ubicación, en esta misma plaza, de lo que se ha interpretado como macellum; por tanto, las mercancías debían llegar para ser vendidas. Este acceso queda garantizado por el lado sur, donde observamos una calle entre el templo dedicado a Tutela y el mismo edificio del mercado. Así pues, la hipótesis presentada por R. Mar (Mar et al., 2012: 327), en la que esta explanada tenía funciones claramente representativas y litúrgicas, se vería reforzada por esta última delimitación de su entorno. La fuente aseguraría que la plaza se preservara como un espacio limpio y libre, y garantizaría la posibilidad de desarrollar los actos religiosos en un marco bien definido.

\section{El ninfeo del Collegium Fabrum}

Entre los años 1928 y 1938, durante el transcurso de unas obras de reforma en los bajos de un inmueble ubicado actualmente en el número 64 de la Rambla Nova de Tarragona, se hallaron restos de muros romanos, así como un gran número de elementos arquitectónicos, epigráficos y escultóricos. Durante las actuaciones de 1928 se localizó una inscripción y en el año 1929, momento en que prosiguieron las obras, 
dichas estructuras arquitectónicas y materiales epigráficos y escultóricos. Entre 1932 y 1938, continuó el hallazgo de restos arqueológicos de época romana. El estudio posterior de las restos escultóricos, llevado a cabo por E. Koppel, determinó una datación del siglo in para todo el conjunto. Las inscripciones encontradas en esta zona fueron estudiadas por G. Alföldy (Macias et al., 2007: 164, f. 686, Costa, 2017: 441) (fig. 8). Las excavaciones arqueológicas de los años treinta abrieron una superficie de 8,82 m por 7,95 y llegaron a una profundidad de 3,80 m. Se encontraron dos muros: los llamados $\mathrm{AB}$ y $\mathrm{CD}$, con una una altura máxima de $2,25 \mathrm{~m}$, obrados con pequeña sillería (Koppel, 1988: 11). El muro AB presentaba una puerta con las jambas realizadas en piedra caliza. En el centro de esa zona de excavación, se localizó una fuente ornamental, cuyos muros mostraban restos de estuco con franjas horizontales de color verde y rojo, imitando el mármol. Esta decoración parietal se reproducía tanto en el muro donde estaba adosada la fuente como en la zona anexa a este sector, y se constató una reforma, en paralelo a la construcción de la fuente, que representó el tapiado de una abertura y la creación de una puerta con dinteles de piedra caliza. Aunque la zona que rodeaba la fuente se encontró ya muy destruida según Navascués, que realizó la excavación, podían reconocerse dos pilares rectangulares de tamaño más reducido que la flanqueaban (Koppel, 1988: 11).

La zona donde se localizaron los restos parece indicar dos fases constructivas: la primera fase nos muestra, en una cota de unos 3,80 m bajo el nivel de la calle actual, la ubicación de uno de los cardines de la ciudad republicana. Prueba de ello fue el hallazgo de un colector central y de dos basamentos de columna o pilastra que indicarían la prolongación de un porticado que se extendía ante la insula que limita la calle por su parte oeste. Estas dos bases, de planta cuadrada, serían la prueba de esta estructura (Mar et al., 2012: 141). En una segunda fase se construyó un edificio que privatizó parte de la calle de época republicana y la dejó sin salida. Uno de los muros de este edificio atravesaba en dirección este-oeste el cardo a unos $8 \mathrm{~m}$ del límite sur de la ínsula. En este muro se encontraba la entrada del edificio citado, casi encima de la antigua alcantarilla. Al lado de esta puerta se construyó, dentro de la zona de ámbito público - lo que queda de la calle - la citada fuente, que tradicionalmente se había considerado parte de la decoración de un ámbito ajardinado del interior del collegium (Mar et al., 2012: 141) (fig. 8).

Este edificio, y por extensión la fuente, se han datado entre la segunda mitad del siglo I dC y las primeras décadas del siglo II. (Mar et al., 2012: 141). A pesar de la divergencia que supone que la fuente no se encuentre dentro del ámbito del collegium, creemos que esta nace gracias a la fundación de la sede colegial. Podemos incluso plantear que, dado que se cortó el paso de una calle con la construcción de la sede, los constructores pudieran haber ofrecido una "compensación" a la ciudadanía en forma de fuente pública, adornada con una decoración escultórica que hiciera evidente el grado de implicación en ofrecer una mejora pública gracias a una contribución privada: un munus (Costa, 2017: 445). 

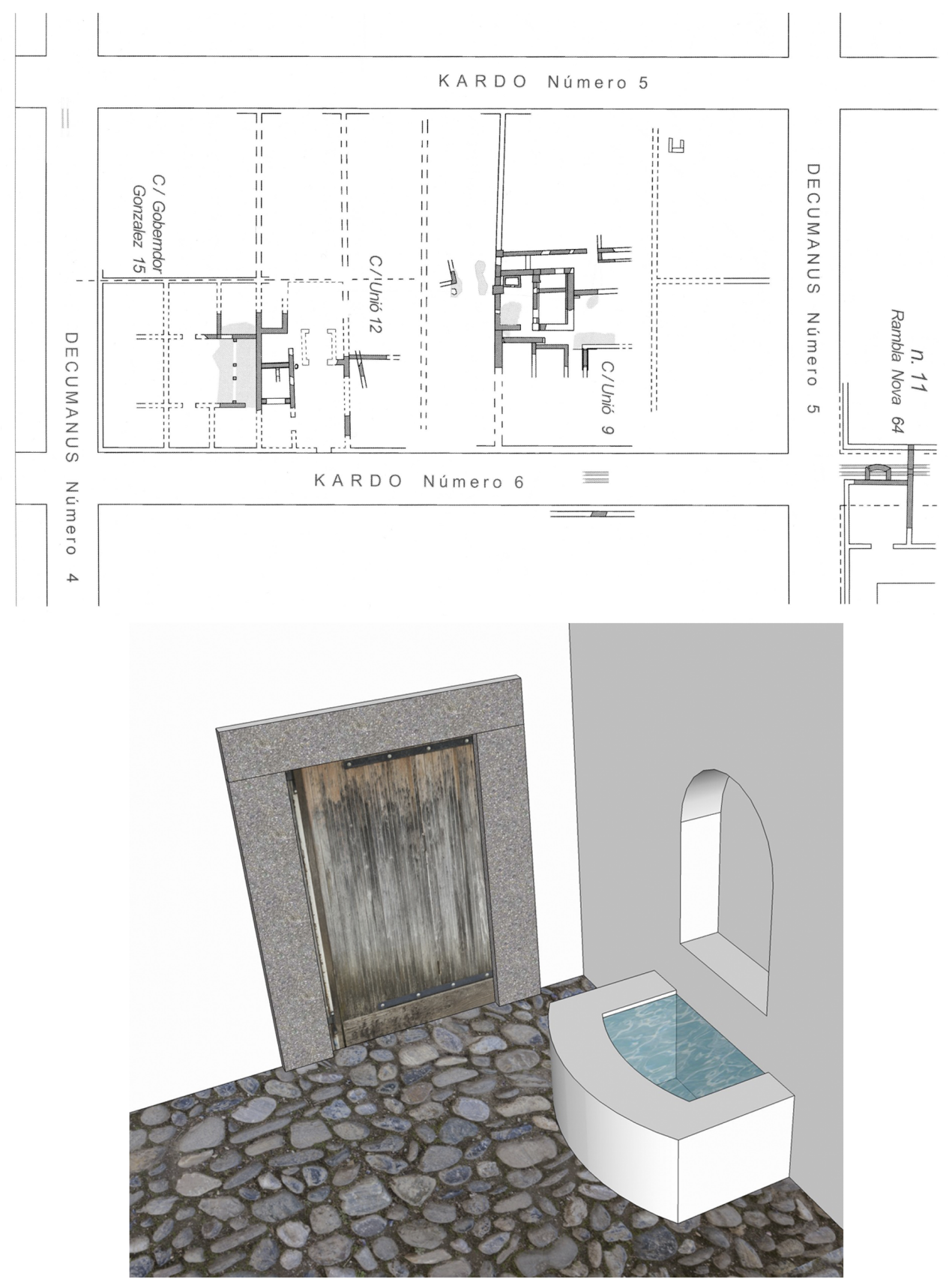

Figura 8. Arriba: planta de la situación de la fuente asociada al Collegium Fabrum (fuente: Mar et al., 2012: 139). Abajo: restitución de la fuente asociada al Collegium Fabrum (fuente: dibujo de la autora). 


\section{Conclusiones}

Aparte de una posible función utilitaria, hay que tener en cuenta una función muy importante de este tipo de arreglos hidráulicos: son una referencia sobre el territorio (Richard, 2008a: 221). Como se puede observar en las pinturas que decoraban las cerámicas arcaicas, la fuente era un punto de reunión, una referencia en el espacio de la ciudad. La situación de estas fuentes dentro del urbanismo acostumbraba a ser la de un espacio privilegiado, donde la fuente se beneficiaba de un entorno adecuado y de un buen acceso. Al mismo tiempo, la plaza o calle donde se inscribía ganaba en belleza, estética y, evidentemente, agua (Costa, 2017: 456-457). El origen de estas fuentes monumentales nace de ejemplares destinados exclusivamente al abastecimiento. El modelo de fuente pública surge de la generosidad los tiranos griegos que en el siglo vII aC regalaron a sus ciudades este tipo de estructuras (Jansen, 2000: 105). Si en un primer momento la necesidad de abastecer de agua a la población era la motivación principal, con el tiempo y sobre todo con las mejoras en ingeniería hidráulica estos puntos de distribución del agua pasarán a ser verdaderas obras arquitectónicas de primer orden con un trasfondo propagandístico. Las grandes fuentes monumentales acercaron el lujo a las clases más populares y al mismo tiempo eran el telón de fondo del discurso imperial, convirtiéndose en uno más de los sistemas de propaganda del poder (Costa, 2017: 470). En el caso de la fuente vinculada al macellum, se encuentra ubicada entre una de las calles que conduce a una de las puertas de entrada a la ciudad y una plaza pública donde se realizaban procesiones vinculadas al culto imperial. En este caso, la fuente funciona como un hito a partir del cual se produce un cambio en el uso del suelo público: una plaza pública donde se desarrollan rituales, actos procesionales oficiales y liturgias vinculadas al poder imperial. Las mejoras en el abastecimiento de agua ayudaron a crear una serie de espacios que, una vez superada esa primera idea funcional de garantizar construcciones de carácter hidráulico, impulsaron el desarrollo de un discurso urbanístico complejo, que, reforzado con recursos arquitectónicos y escultóricos, facilitó la transmisión de una imagen de poder y prosperidad junto con la idea de protección y dicha. Este discurso, vehiculado gracias al agua, fue un recurso utilizado tanto por las élites locales como por el poder imperial para transmitir sus ideas (Costa, 2017: 471). 


\section{Bibliografía}

ÁLVAREZ, J. M. y NOGALES, T,. 2003, Forum Coloniae Augustae Emeritae. Templo de Diana, Asamblea de Extremadura, Mérida.

BEA, D., 2006, El port romà de Tarraco, aportacions historiogràfiques i noves interpretacions. La intervenció arqueològica als solars de l'UA 15 de Tarragona (Tarragonès), Tribuna d'Arqueologia 2004-2005, Barcelona, 215-244.

BURÉS, L., GARCÍA, M. y MACIAS, J. M., 1998, Un aqüeducte subterrani a Tàrraco, Empúries 51, 183-196.

BURÉS, L., GARCIA, M. y MACIAS, J. M., 2000, Tarraco Scipionum opus. A Roman Spanish city built on karst, Cura aquorum in Sicilia. Proceedings of the tenth international congress on the history of water management and hydraulic engineering in the Mediterranean region (Siracusa 1998), Leiden, 79-84.

COSTA, A., 2011, El agua en Tarraco, Aquae Sacrae. Agua y sacralidad en la Antigüedad, Actas de la reunión internacional, Girona, 12-13 julio de 2011, Gerona, 141-166.

COSTA, A., 2017, Aigua sagrada i aigua monumental al nord-est de la Península Ibèrica en l'època romana, Universitat de Girona (tesis doctoral).

CUCHÍ, T., 1875, Descripción de las aguas de Tarragona y algunas de la provincia, Tarragona.

CUESTA, R., 2011, Cueva Román: Fuente de abastecimiento - Lugar de culto de la Colonia Clunia Sulpicia, en A. COSTA, L. PALAHÍ y D. VIVÓ (coord.), Aquae sacrae, agua y sacralidad en la Antigüedad, Universitat de Girona, Institut de la Recerca Històrica, Gerona, 167-180.

DE RUYT, C., 1983, Macellum. Marché alimentaire des romains, Inst. Sup. d'Archéologie et d'Histoire de l'Art, Lovaina la Nueva.

GARCÍA MORCILLO, M., 2000, El Macellum Magnum y la Roma de Nerón, Iberia 3, 265-285.

GLASER, F., 2000, Fountains and nymphaea, en Ö. WIKANDER (ed.), Handbook of ancient water Technology, Brill, Leiden-Boston-Colonia, 413-451.
HAUSCHILD, T., 1994, El templo romano de Évora, nuevas investigaciones, La Ciudad en el mundo romano. Actas XIV Congreso Internacional de Arqueología Clásica, septiembre de 1993, vol. 2, Tarragona, 97-200.

HODGE, A. T., 2000, Aqueducts, en Ö. WIKANDER (ed.), Handbook of ancient water Technology, Brill, Leiden-Boston-Colonia, 39-65

JANSEN, G. C. M., 2000, Urban water transport and distribution, en Ö. WIKANDER (ed.), Handbook of ancient water Technology, Brill, LeidenBoston-Colonia, 103-125.

JIMÉNEZ SALVADOR, J. L., 1993, Teatro y desarrollo monumental urbano en Hispania, Teatros romanos de Hispania, Cuadernos de arquitectura romana 2, Murcia, 225-238.

KOPPEL, E., 1988, La schola del collegium fabrum de Tarraco y su decoración escultórica, Faventia 7 , Monografies, Universitat Autònoma de Barcelona, Barcelona.

KOPPEL, E. y RODÀ, I., 1996, Escultura decorativa de la zona nororiental del Conventus Tarraconensis, en J. MASSÓ y P. SADA (eds.), II Reunión sobre escultura romana a hispania, (Tarragona, 1995), Tarragona, 135-191.

MACIAS, J. M. y PUCHE, J. M., 2004, El cuniculus de Tàrraco: tècnica i anàlisi d'una obra amagada, Tàrraco i l'aigua, Catàleg de l'exposició MNAT, Tarragona, 37-50.

MACIAS, J. M. y REMOLÀ, J. A., 2010, Portus Tarraconensis (Hispania Citerior), Bollettino di Archeologia on line I 2010/ Volume speciale B / B7 / 10. 129-140, <www.archeologia.beniculturali.it/ pages/pubblicazioni.html>.

MACIAS, J. M., 1997, Memòria de la intervenció arqueològica efectuada al solar núm. 32 del carrer Gasòmetre, Tarragona, Tarragona.

MACIAS, J. M., 2011, Horrea y estructuras de almacenamiento en la ciudad y territorio de Tarraco. Una primera aproximación, en J. ARCE 
y B. GOFFAUX (eds.), Horrea d'Hispanie et de la Méditerranée romaine, Casa de Velázquez, Madrid, 185-199.

MACIAS, J. M., FIZ, I., PIÑOL, L., MIRÓ, M. T., GUITART, J., 2007, Planimetria arqueològica de Tarraco, Institut Català d'arqueologia Clàssica, Tarragona, Serie Documenta 5.

MACIAS, J. M., MORERA, J., OLESTI, O. y TEIXELL, I., 2013, Crisi o invasió? Els Francs i la destrucció parcial de Tàrraco a s. III, en J. VIDAL y B. ANTELA (coord.), Más allá de la batalla. La violencia contra la población en el Mundo Antiguo, Zaragoza, 193-214.

MAR, R., RUIZ DE ARBULO, J., VIVÓ, D., DOMINGO, J. y LAMUÁ, M., 2010, La Scaenae frons del teatro de Tarraco. Una propuesta de restitución, La Scaenae Frons en la arquitectura teatral romana, Actas del symposium Internacional celebrado en Cartagena los días 12 al 14 de marzo de 2009, Universidad de Murcia, Murcia, 173-201.

MAR, R., RUIZ DE ARBULO, J., VIVÓ, D. y BELTRÁN-CABALLERO, J. A., 2012, Tarraco, Arquitectura y urbanismo de una capital provincial romana, Volumen I. De la Tarragona ibérica a la construcción del templo de Augusto, Documents d'Arqueologia Clàssica 5, Tarragona.

MAR, R., 1992, El teatro de Tarragona y el santuario de Hércules en Ostia - Dos elementos en la transformación de las ciudades del occidente romano durante los siglos II y III d.C., Die römische Stadt im 2. Jahrhundert n. Chr. der Funktionswandel des öffentlichen Raumes, Colonia, 163-181.

MAR, R., ROCA, M. y RUIZ DE ARBULO, J., 1993, El teatro romano de Tarragona: un problema pendiente, Cuadernos de arquitectura romana 2, Murcia, 11-23.

NEUERBURG, N., 1965, L'architettura delle fontane e dei ninfei nell'Italia antica, Accademia di Archeologia Lettere e Belle Arti di Napoli, Nápoles.

PALMA, A. DE, 1958, Las calles antiguas de Tarragona (s. XIII-XIX), Tarragona.

POCIÑA, C. y REMOLÁ, J., 2001, Nuevas aportaciones al conocimiento del puerto de
Tarraco (Hispania Tarraconensis), Saguntum, Papeles del Laboratorio de Arqueología de Valencia 33, Valencia, 85-96.

POCIÑA, C. y REMOLÁ, J., 2002, Una font monumental a l'àrea portuària de Tarraco. Notes preliminars, Empúries 53, Barcelona, 41-47.

REIS, M. A. P., 2010, Tanques, fontes e espelhos de água nos fora lusitanos, en T. NOGALES (ed.), Ciudad y foro en Lusitania Romana, Badajoz, 285-314.

REMOLÀ, J. y POCIÑA, C. 2004, La Font dels Lleons, Catàleg de l'exposició Tàrraco i l'aigua, MNAT, Tarragona, 53-66.

REMOLÀ, J. y POCIÑA, C., 2011, La Font dels Lleons (Tarragona), en A. COSTA, L. PALAHÍ y D. VIVÓ, (coords.), Aquae sacrae, agua y sacralidad en la Antigüedad, Universitat de Girona, Institut de la Recerca Històrica, Gerona,181-192.

REMOLÀ, J. A. y RUIZ DE ARBULO, J., 2002, El agua en la colònia de Tarraco, Empúries 53, 29-65.

RICCIARDI, M. A. y SCRINARI, V. S. M., 1996, La civilta dell'acqua in Ostia antica, Roma.

RICHARD, J., 2008, Roman monumental fountains in the Levant: Water Supply vs. Urban Aesthetics? Cura Aquarum in Jordanien, Proceedings of the $13^{\text {th }}$ International Conference on the History of water. Management and Hydraulic engineering in the Mediterranean Region, Petra, 263-284.

RICHARD, J., 2008a, La fontaine monumentale romaine et l'espace de la rue: le cas de Sagalassos, La rue dans l'antiquité: définition, aménagement, devenir. Actes du colloque de Poitiers, 7-9 septembre 2006, Rennes, 215-222.

RUIZ DE ARBULO, J., 1991, El templo del foro de Ampurias y la evolución de los foros republicanos, Templos romanos de Hispania, Cuadernos de arquitectura romana, vol. 1, 11-37.

RUIZ DE ARBULO, J., MAR, R., ROCA, M. y DÍAZ, M., 2010, Un contexto cerámico de fines del siglo i a.C. como relleno constructivo de un almacén portuario localizado bajo el teatro romano de Tarragona, Contextos ceràmics $i$ cultura material d'època augustal a l'occident romà, Universitat de Barcelona (CDROM). 
RUIZ DE ARBULO, J. MAR, R. BELTRÁNCABALLERO, J. A., COSTA, A., GRIS, F. Y GUIDI-SÁNCHEZ, J. J., 2015, La gestión del agua en la antigua Tarraco, Aquae ductus. Actualité de la recherche en France et en Espagne, Actes du colloque international, le 15-16 février 2013 à Toulouse, Suppl. Aquitania, 117-137.
WILSON, A., 2000, Land drainage, Handbook of ancient water Technology, en Ö. WIKANDER (ed.), Handbook of ancient water Technology, Brill, LeidenBoston-Colonia, 303-317. 
